In collaboration with Department of the Interior Data Resource Management in Support of the Department of the Interior Metadata Approach

\title{
Department of the Interior Metadata Implementation Guide- Framework for Developing the Metadata Component for Data Resource Management
}

Chapter 1 of

Section A, Metadata Book 16, Data Resource Management.

Techniques and Methods 16-A1

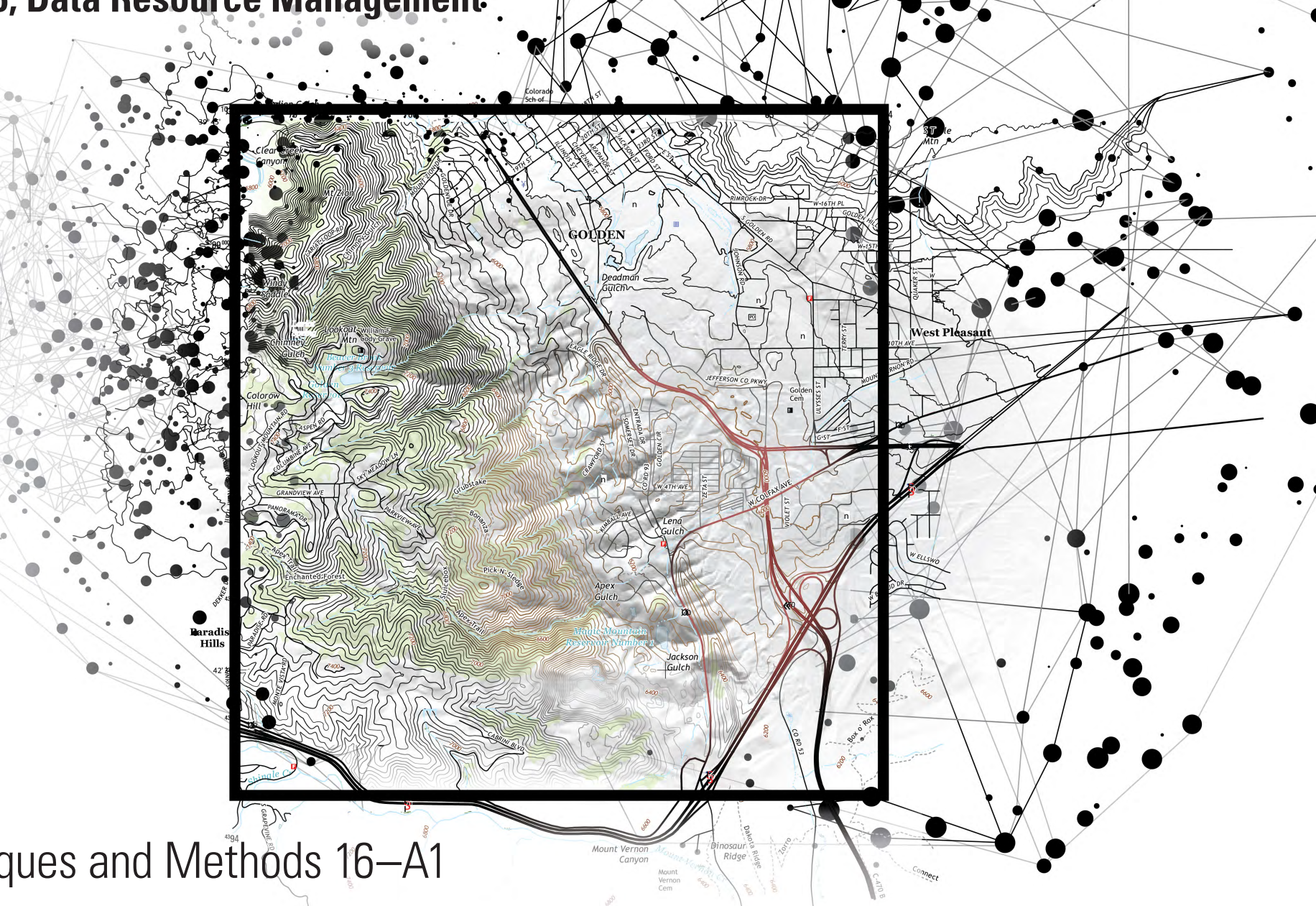


Cover. Golden, Colorado area. (digital elevation model metadata from U.S Geological Survey, The National Map, 2018) 


\section{Department of the Interior Metadata Implementation Guide-Framework for Developing the Metadata Component for Data Resource Management}

By Raymond C. Obuch, Jennifer Carlino, Lin Zhang, Jonathan Blythe, Chris Dietrich, and Christine Hawkinson

Chapter 1 of

Section A, Metadata

Book 16, Data Resource Management

In collaboration with Department of the Interior Data Resource Management in Support of the Department of the Interior Metadata Approach

Techniques and Methods 16-A1 


\title{
U.S. Department of the Interior \\ RYAN K. ZINKE, Secretary
}

\section{U.S. Geological Survey William H. Werkheiser, Deputy Director exercising the authority of the Director}

\author{
U.S. Geological Survey, Reston, Virginia: 2018
}

For more information on the USGS - the Federal source for science about the Earth, its natural and living resources, natural hazards, and the environment-visit https://www.usgs.gov or call 1-888-ASK-USGS.

For an overview of USGS information products, including maps, imagery, and publications, visit https://store.usgs.gov.

Any use of trade, firm, or product names is for descriptive purposes only and does not imply endorsement by the U.S. Government.

Although this information product, for the most part, is in the public domain, it also may contain copyrighted materials as noted in the text. Permission to reproduce copyrighted items must be secured from the copyright owner.

Suggested citation:

Obuch, R.C., Carlino, Jennifer, Zhang, Lin, Blythe, Jonathan, Dietrich, Chris, Hawkinson, Christine, 2018, Department of the Interior metadata implementation guide-Framework for developing the metadata component for data resource management: U.S. Geological Survey Techniques and Methods, book 16, chap. A1, 14 p., https://doi.org/10.3133/tm16A1.

ISSN 2328-7055 (online) 


\section{Preface}

The Department of the Interior (DOI) is committed to defining, creating, managing, using, and sharing high-quality data. The purpose of the DOI Metadata Implementation Guide is to provide suggestions for creating and maintaining metadata for $\mathrm{DOI}$-owned data sources. These documents were developed in consensus by data professionals from the DOI bureaus and offices and are based on an understanding of existing metadata practices and requirements from Federal statutes, regulations, Executive Orders, and Presidential Memoranda.

The implementation guide includes a referenced framework of best practices, methodologies, processes, and common approaches; suggested roles and responsibilities; success indicators and metrics; and recommended steps to implement and advance metadata management across DOI. Implementing metadata management will provide a common framework which may vary by bureau or office depending on specific requirements. Metadata management is crucial for providing information about DOI data and an important component within the DOI data resource management (DRM) strategy. Successful metadata management provides tangible benefits to the $\mathrm{DO}$ l because it:

1. Documents the data;

2. Facilitates integration and coordination of metadata activities with other data management activities at all levels of DOl;

3. Provides common milestones and products for metadata activities;

4. Ensures a common understanding of data and the foundation to share, discover, and use data for intended purposes; and

5. Enables institutionalization of metadata management.

The intended audience for these documents includes leadership and executives, data stewards, data professionals, scientists, information technology (IT) specialists, and other DOI employees, with each group being responsible for various aspects of metadata management.

\section{Acknowledgments}

The authors would like to acknowledge the contributions from other members of the DOI metadata implementation team consisting of Ralph Johnson (Office of Natural Resources Revenue), George Wilson (Bureau of Land Management), and Rachel Dimmit (Bureau of Land Management) for their knowledge, input regarding metadata management, and content editing. A special thanks is given to Rachel Dimmit for extensive formatting and style improvements, Julie Binder Maitra (U.S. Geological Survey) and Ben Wheeler (U.S. Geological Survey) for their extensive review and edits, and the bureau data representatives who attended the Fall 2014 metadata workshop. 



\section{Contents}

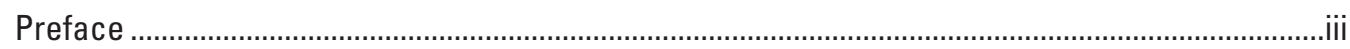

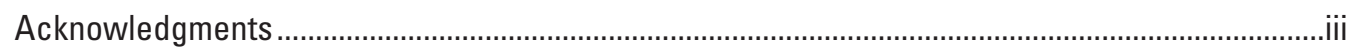

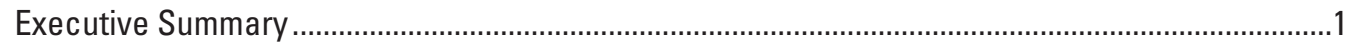

Importance of Data as an Organizational Asset........................................................................

Why Engage in Metadata Management? ..................................................................................

Where Metadata Management Fits in Your Organization............................................................

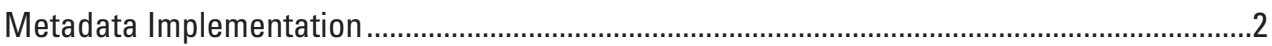

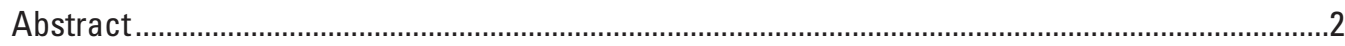

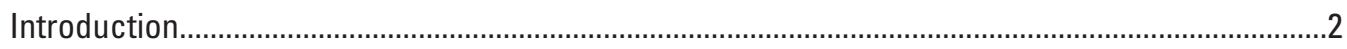

Long-Term Goals and Benefits of Managing Metadata ........................................................

Metadata Types................................................................................................................

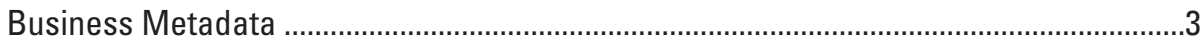

Operational Metadata ……………..............................................................................

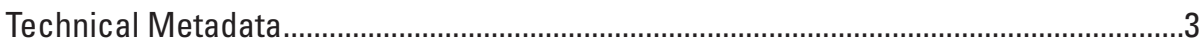

Metadata for Data Search, Data Discovery, and Data Use...............................................

How Bureaus and Offices Use this Guide ...........................................................................

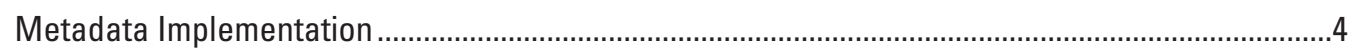

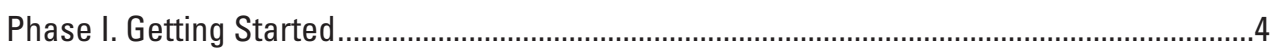

Action 1.1. Identify Documentation Issues with Current Data Holdings ...........................5

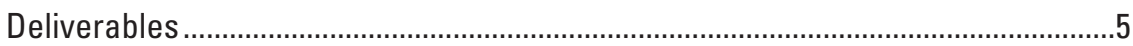

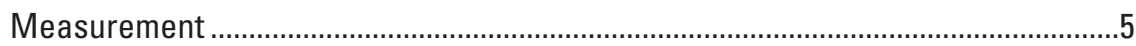

Action 1.2. Scope Metadata Types ……………………............................................

Description

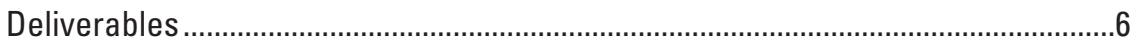

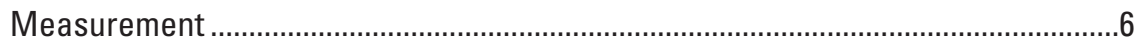

Action 1.3. Establish Roles and Identify Points of Contact ................................................

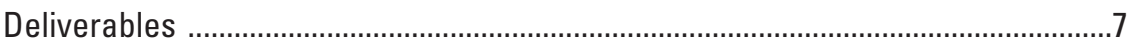

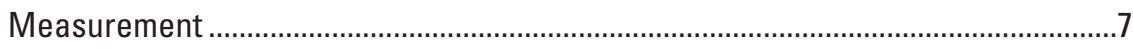

Action 1.4. Participate in Metadata Communities of Practice ..........................................7

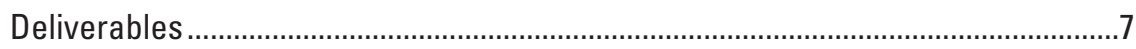

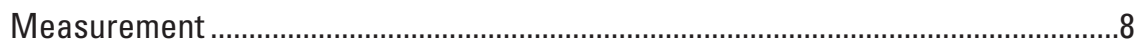

Action 1.5. Develop Communication Strategy ..............................................................

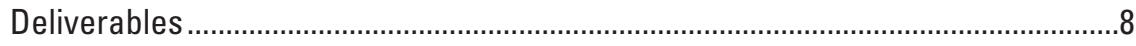

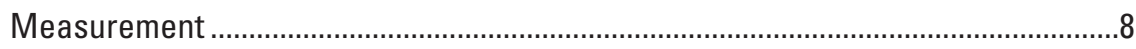

Action 1.6. Identify Metadata Standards ......................................................................

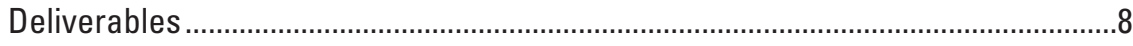

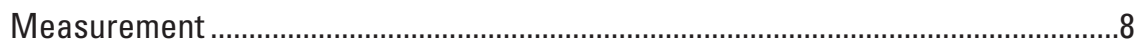

Action 1.7. Select Metadata Management Tools ………...............................................

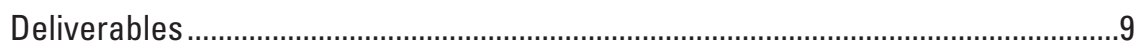

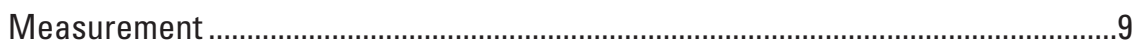

Phase II. Implement and Manage Metadata ………...........................................................

Action 2.1. Create and Maintain Metadata .................................................................

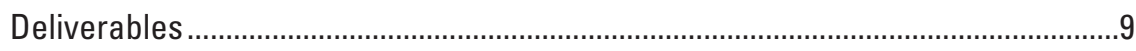

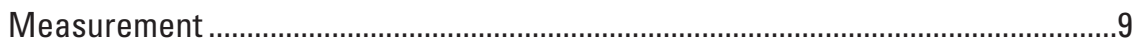




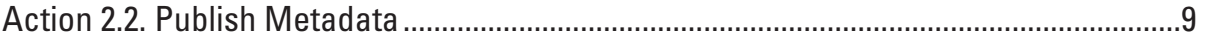

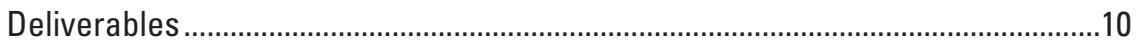

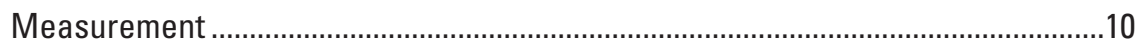

Phase III. Improving Metadata Management........................................................................11

Action 3.1. Evaluate Metadata Implementation...............................................................11

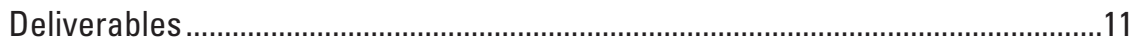

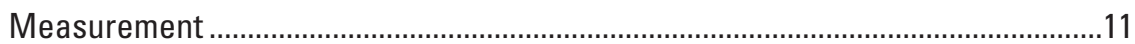

Action 3.2. Develop and Enforce Metadata Quality Standards.........................................11

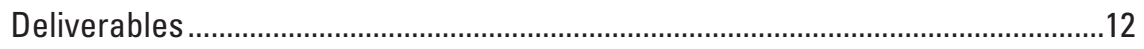

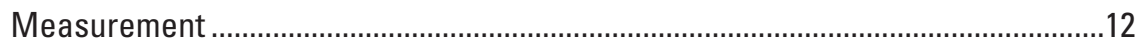

Action 3.3. Create Shared Metadata and Metadata Infrastructure ...............................12

Deliverables ......................................................................................................13

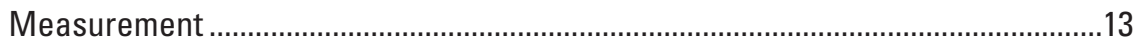

Action 3.4. Increase Data Access and Usability for Target Audiences..........................13

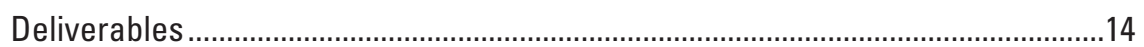

Measurement .................................................................................................... 14

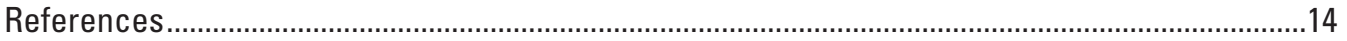

\section{Figures}

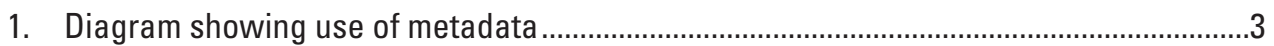

2. Diagram showing publishing metadata to the DOI Metadata Catalog (from Frame and Wheeler, 2014) ...........................................................................................

\section{Tables}

1. Implementation Guide Responsibility Chart (RASCI) ……................................................

2. Employees and other data management personnel and their functional role(s)..............7

3. Metadata management capability (maturity) levels of design structure matrix (DMS) (copyright CMMI Institute, 2014) 


\title{
Department of the Interior Metadata Implementation Guide-Framework for Developing the Metadata Component for Data Resource Management
}

\author{
By Raymond C. Obuch, ${ }^{1}$ Jennifer Carlino, ${ }^{4}$ Lin Zhang, ${ }^{2}$ Jonathan Blythe, ${ }^{3}$ Chris Dietrich, ${ }^{4}$ \\ and Christine Hawkinson ${ }^{5}$
}

\section{Executive Summary}

After the Office of Management and Budget issued Memorandum M-13-13 Open Data Policy (Office of Management and Budget, 2013) in May 2013, the Department of the Interior (DOI) and other Federal agencies began developing an Enterprise Data Inventory. This process provided DOI the impetus to work towards an enterprise approach to implement and manage metadata. This Metadata Implementation Guide (MIG) was developed collaboratively and by consensus with subject matter experts from all DOI bureaus and offices.

The MIG provides a common metadata management framework across DOI and includes recommendations for planning, managing, and improving metadata management and implementation. Bureaus and offices will design their own implementation plans to best focus and pace the advancement of metadata management to meet specific needs and requirements.

\section{Importance of Data as an Organizational Asset}

DOI views data as a shareable resource. At the organizational level, decisions, analysis, research, scientific findings, and knowledge transfer are all based on data. Having a better understanding of the data through properly documented metadata is a cornerstone to all functions of an organization. Good metadata allow the user to find and evaluate data with regard to provenance, meaning, accuracy, and quality.

\footnotetext{
${ }^{1}$ U.S. Geological Survey.

${ }^{2}$ Department of the Interior.

${ }^{3}$ Bureau of Ocean Energy Management.

${ }^{4}$ National Park Service.
}

${ }^{5}$ Bureau of Land Management.

\section{Why Engage in Metadata Management?}

Federal data policies, directives, and mandates require bureaus and offices to implement Data Resource Management. This includes documenting and registering data assets through metadata to facilitate discovery, access, and use of agency data. All DOI datasets must be registered in the DOI Metadata Catalog at a minimum, except for where restricted from disclosure in accordance with statute, regulation, Executive Order, or Presidential Memoranda.

Furthermore, the general public expects the government to pursue increased transparency by making relevant data and information publicly available. Metadata management helps DOI and its bureaus and offices maximize the value of data for internal users and the public by improving knowledge of data quality, providing data transparency, reducing data redundancies, citing data sources, supporting data lifecycle management, empowering business staff, and underlining the importance of reliable data for effective decisions. Effective metadata management creates an environment that supports specific data release requirements and workflows for data security, records management, Freedom of Information Act, privacy, legal, communications, and acquisition processes.

\section{Where Metadata Management Fits in Your Organization}

Data and metadata need to be managed before they are incorporated into any information system. Data Resource Management follows a data lifecycle that connects data stewards within programs, data professionals and IT specialists who manage and provide data services, employees who use data for analysis or information purposes, and executives who make decisions based on data. Bureaus and offices need to actively engage, communicate, train, and assign clear roles for implementing metadata management. 


\section{Metadata Implementation}

The MIG provides general direction and recommends resources and best practices to guide metadata management through the formulation of a framework in support of DOI metadata management. It offers a modular approach, whereby metadata management actions are presented in a linear sequence, but can be considered and applied independently in any order based on specific business needs, policies, mandates, budgets, and priorities. Bureaus and offices are encouraged to leverage existing best practices and use this guide to aid in implementing DOI metadata requirements.

Successful implementation of DOI metadata may be hindered by a number of factors including lack of metadata requirements, time and budget constraints, and difficulties in consistently implementing metadata across the enterprise. Key factors for a favorable outcome include gaining senior management appreciation for the value of metadata, establishing a self-paced approach for metadata implementation, developing internal bureau or office procedures to select and comply with metadata standards, and actively engaging relevant participants early in the metadata implementation process. Periodic measurement of overall metadata implementation progress and success through defined metrics support the overall goal of maximizing the value of data.

The DOI data governance body, represented by bureau and office data leads, will serve as the reviewing and approving authority for metadata. The purpose, goals, and other duties will be specified in its charter. This group will also review and accept any recommendations or changes to the metadata approach and implementation guide as necessary or appropriate.

\section{Abstract}

The Department of the Interior (DOI) is a Federal agency with over 90,000 employees across 10 bureaus and 8 agency offices. Its primary mission is to protect and manage the Nation's natural resources and cultural heritage; provide scientific and other information about those resources; and honor its trust responsibilities or special commitments to American Indians, Alaska Natives, and affiliated island communities. Data and information are critical in day-to-day operational decision making and scientific research. DOI is committed to creating, documenting, managing, and sharing high-quality data and metadata in and across its various programs that support its mission. Documenting data through metadata is essential in realizing the value of data as an enterprise asset. The completeness, consistency, and timeliness of metadata affect users' ability to search for and discover the most relevant data for the intended purpose; and facilitates the interoperability and usability of these data among DOI bureaus and offices. Fully documented metadata describe data usability, quality, accuracy, provenance, and meaning.
Across DOI, there are different maturity levels and phases of information and metadata management implementations. The Department has organized a committee consisting of bureau-level points-of-contacts to collaborate on the development of more consistent, standardized, and more effective metadata management practices and guidance to support this shared mission and the information needs of the Department. DOI's metadata implementation plans establish key roles and responsibilities associated with metadata management processes, procedures, and a series of actions defined in three major metadata implementation phases including: (1) Getting started-Planning Phase, (2) Implementing and Maintaining Operational Metadata Management Phase, and (3) the Next Steps towards Improving Metadata Management Phase. DOI's phased approach for metadata management addresses some of the major data and metadata management challenges that exist across the diverse missions of the bureaus and offices. All employees who create, modify, or use data are involved with data and metadata management. Identifying, establishing, and formalizing the roles and responsibilities associated with metadata management are key to institutionalizing a framework of best practices, methodologies, processes, and common approaches throughout all levels of the organization; these are the foundation for effective data resource management. For executives and managers, metadata management strengthens their overarching views of data assets, holdings, and data interoperability; and clarifies how metadata management can help accelerate the compliance of multiple policy mandates. For employees, data stewards, and data professionals, formalized metadata management will help with the consistency of definitions, and approaches addressing data discoverability, data quality, and data lineage. In addition to data professionals and others associated with information technology; data stewards and program subject matter experts take on important metadata management roles and responsibilities as data flow through their respective business and science-related workflows. The responsibilities of establishing, practicing, and governing the actions associated with their specific metadata management roles are critical to successful metadata implementation.

\section{Introduction}

The Department of the Interior Metadata approach encourages each bureau and office to establish formal metadata management and develop a metadata management implementation plan. Implementation plans should be based on operational and research priorities, and management and administrative or overall mission needs of the bureau or office, in collaboration with other bureaus and offices to facilitate consistency across DOI. 


\section{Long-Term Goals and Benefits of Managing Metadata}

Well-documented data are an integral part in establishing the value of data as an enterprise asset. Implementing the guidance and best practices referenced in the MIG will help bureaus and offices maximize the value of their data in the following ways:

1. Documenting an integral business asset.

2. Data sharing across bureaus in the department. Metadata provide information about data security, origin, and purpose.

3. Consistent definitions. Metadata schemas and documentation standards provide a framework where controlled vocabularies and taxonomies can be used to help describe data in a more consistent way based on business, science, and other community needs.

4. Searching, discovering, and using data. Metadata contain data fields such as location, topic, and data release date that make it easier to find necessary data and use data for their intended purpose.

5. Improved understanding of data quality. Metadata elements are created and structured under a common set of standards, and business rules can be consistently documented, controlled, and validated. This leads to well-supported decisions, strong analysis, meaningful research, valid scientific findings, and successful knowledge transfer.

6. Clarity of data relations. Metadata help resolve ambiguity and inconsistencies related to data understanding and use across organizations by documenting data entity definitions and their associations to other data entities within and across data domains and other information sources.

7. Identify redundancies in data. Metadata help identify what data exist and which data are authoritative.

8. Support data lifecycle management. Robust documentation supports all types of metadata (business, operational, and technical) and the data lifecycle.

9. Promote interoperability. Metadata management promotes the use of common standards across DOI and fosters increased data interoperability across diverse disciplines and mission areas.

See Understanding Metadata by the National Information Standards Organization (2004), for additional information.

\section{Metadata Types}

Bureaus and offices may use different types of metadata in their metadata management activities to accomplish their mission objectives. These metadata types include business, operational, and technical.

\section{Business Metadata}

The Data Management Association International defines business metadata in Mosley and others (2009, p. 262) as, "the business names, the definitions of subject and concept areas, entities, and attributes; attribute data types and other attribute properties; range descriptions; calculations; algorithms and business rules; and valid domain values and their definitions. Business metadata relates the business perspective to the metadata user." This is further explained in Early (2011, p. 166) as, "of interest to business professionals [and] ideally defined by business data stewards."

\section{Operational Metadata}

Operational or administrative metadata are defined in Early (2011, p. 166) as, "metadata that records lifecycle attributes of a resource, including acquisition, access rules, locations, version control [or] differentiation, lineage, and archival [or] destruction."

\section{Technical Metadata}

Early (2011, p. 167) defines technical metadata as the "physical characteristics of data found in a database, including physical names, data types, lengths, precision and scale of numeric data attributes, statistics, source location (lineage), location of data stores and interfaces, and code values. It may also include data about programs and other technology."

\section{Metadata for Data Search, Data Discovery, and Data Use}

The information contained in metadata elements supports different needs and requirements depending on the audience. There is a need for more detailed metadata to support data search, discovery and use as illustrated in figure 1 .

Understanding the roles and responsibilities and assigning responsibility for metadata management are critical to the success of its implementation as represented in table 1.

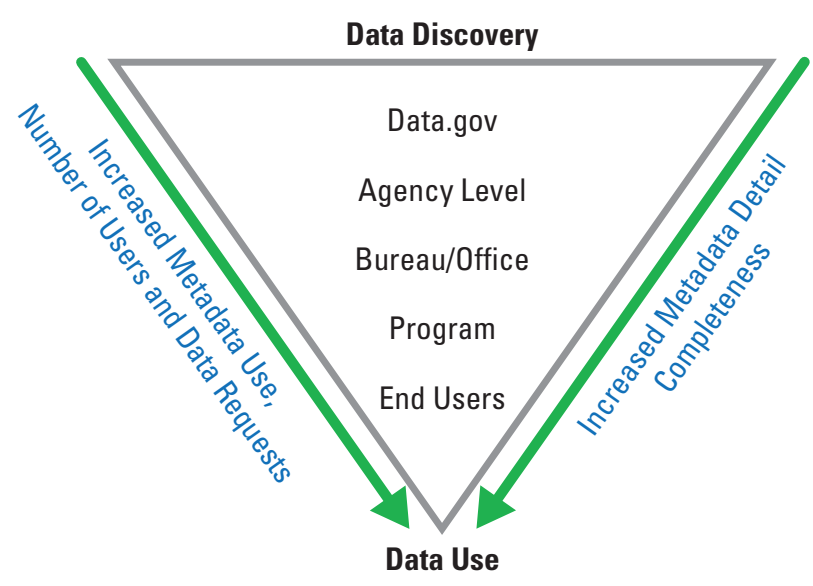

Figure 1. Use of metadata. 
Table 1. Implementation Guide Responsibility Chart (RASCI).

[DOI Department of the Interior; Responsible, An entity or person assigned to do the work; Accountable, An entity or person who makes the final decision and has ultimate ownership; Support, An entity or person who helps complete the tasks; Consult, An entity or person who must be conferred with before a decision or action can be taken; Inform, An entity or person who must be made aware that a decision or action is pending or has been taken]

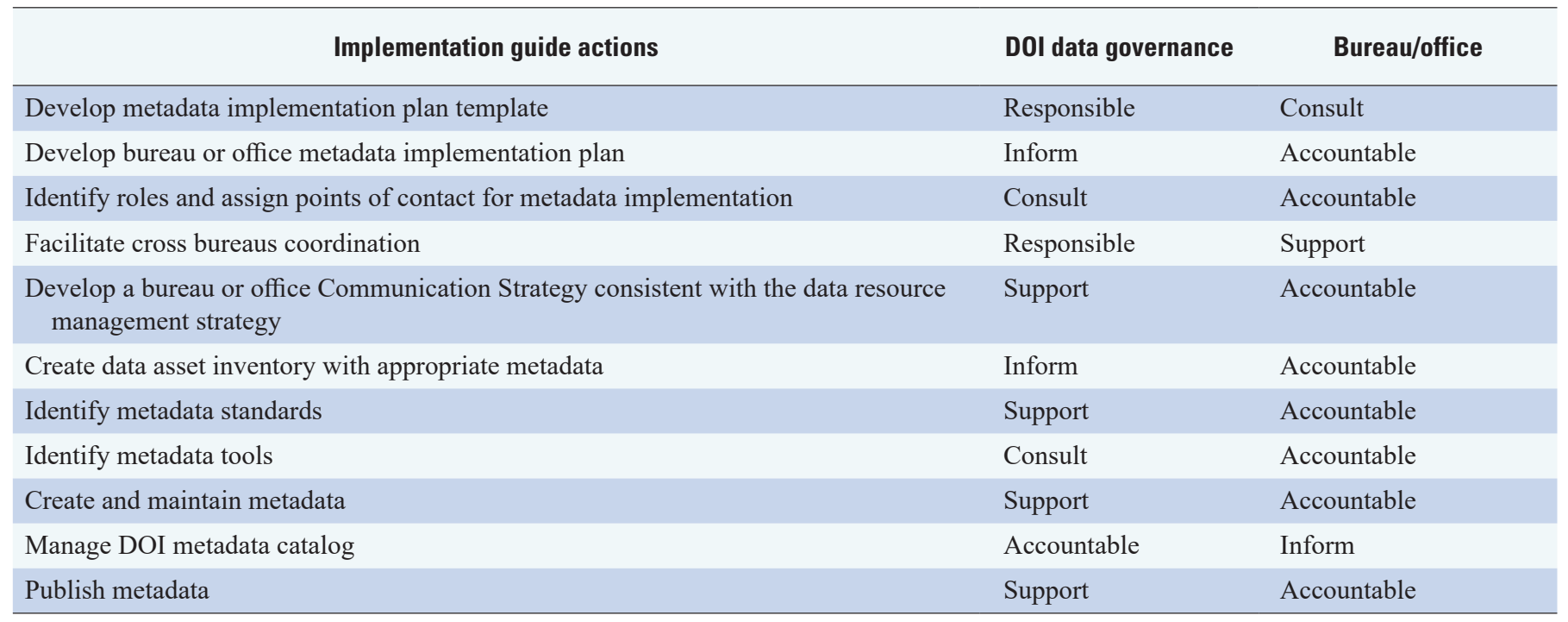

\section{How Bureaus and Offices Use this Guide}

The MIG provides a framework of documented processes, methods, and procedures to consult when developing individual bureau or office implementation plans. This guide consists of three major sections (phases):

1. Getting Started.

2. Implement and Manage Metadata.

3. Improving Metadata Management.

Each MIG section contains specific actions, and each action includes

1. Key Drivers. Reasons why an action needs to occur.

2. Description. Steps and processes that support completion of the action.

3. Dependencies. People, processes, and funding that are required for success of that action.

4. Responsible Roles. Work and associated responsibilities that need to be assigned to individuals to complete the action.

5. Deliverables. Expected outcomes and products resulting from the action.

6. Measurements. Metrics used to measure the success of an action, usually tied to deliverables.

7. Recommended Methods and Tools. References for metadata implementation, best practices, and case studies.
The actions contained in the MIG can be used or adapted to fit a bureau or office's data priorities and the current capability and maturity level of metadata management. The MIG is a living document that provides general direction and resources and sets expectations for metadata management. Bureaus and offices will augment the MIG with their own approach to help meet long-term data and metadata goals and objectives.

Metadata work can be prioritized based on program, geographic area, or a particular data domain, and may initially focus on one area as a proof of concept. Ultimately, managing metadata and maturing metadata management are not discrete projects; bureaus and offices should have long-term goals with step-by-step plans to achieve them. This requires incorporation of metadata requirements from functional areas such as data security, records management, Freedom of Information Act (FOIA), privacy, legal, communications, acquisitions, and contracting processes.

\section{Metadata Implementation}

Metadata implementation is described across three phases, beginning with "Getting Started," then moving into implementing and managing metadata, to the final phase of overall improvement of metadata management.

\section{Phase I. Getting Started}

This section focuses on the activities required to establish the foundational aspects and requirements for successful bureau or office metadata management. This includes identifying the 
proper organizational level and staff to communicate the message, supporting the development of a data inventory, facilitating creation of metadata, and identifying the tools and applications needed to operationalize metadata management efforts.

\section{Action 1.1. Identify Documentation Issues with Current Data Holdings}

Drivers. The purpose of this action is to plan and prioritize activities for metadata implementation and management, and to identify missing and incomplete metadata associated with existing data.

Description. This action involves performing a baseline inventory of data and metadata holdings, including digital and paper materials, to facilitate the identification and prioritization of next steps in metadata implementation and management. In addition, metadata records should be reviewed for completeness and robustness based on bureau or office business and science needs. Data stewards and managers need to review metadata elements and registration requirements, and evaluate the completeness of metadata records to facilitate data discovery and sharing.

This can be implemented in stages based on bureau or office data priorities and resource constraints. The data holdings inventory and metadata gap analysis, along with bureau or office priorities and requirements, will help develop the metadata approach regarding standards, level of documentation, and methods. These gap analyses should be done in cooperation with data security, records management, FOIA, privacy, legal, communications, acquisitions, and contracting personnel to help formulate any additional metadata requirements.

Dependencies. The bureau or office must have staff with the appropriate skills and knowledge necessary to facilitate the development and completion of the data inventory and metadata gap analysis, and formulate metadata requirements, priorities, and next steps.

Responsible Roles. Each bureau and office must assign the appropriate personnel needed to successfully complete the action. Ultimately, each bureau and office should strive to institutionalize roles and responsibilities through more permanent job assignment or position titles such as data steward, data manager, data scientist, and (or) line of business representatives.

\section{Deliverables}

1. A prioritized inventory of data assets accompanied by a listing of corresponding metadata records that meets bureau or office organizational needs, as well as its level of completion.

2. A gap analysis report that describes the status of each dataset, its associated metadata record and metadata type(s), and recommendations on any metadata improvements.

\section{Measurement}

1. The level of completion of the data inventory along with a metadata gap analysis across various program and mission areas.

2. A prioritized list of datasets that require additional metadata and documented next steps for furthering metadata management.

Recommended Methods and Tools. References for metadata implementation, best practices, and case studies.

\section{Action 1.2. Scope Metadata Types}

Drivers. In order to address the extent of metadata that is needed to adequately document data to meet organizational needs, an assessment of the current level of documentation that exists for the metadata types is needed. All three types of metadata need to be included in this assessment, with organizational requirements driving of the level of documentation required for each metadata type.

\section{Description}

Business Metadata. Business metadata are usually the first type of metadata to be developed. They provide a detailed description of data elements such as data element names, data types, data definitions, and data domain values. They provide information that promotes shared understanding of data, enhances data interoperability, and simplifies data integration.

Business metadata need to be reviewed and updated only if the actual database schema or entities changes. When creating operational or technical metadata, the existing business metadata should be linked to the complete metadata record and not redefined.

Operational Metadata. Operational or administrative metadata provide information about how the data are being managed and used. These metadata include information on access rights, how and when the data were created, the currency or version of the data, and an indication of their overall quality. This type of metadata is important for supporting data and information-related processes associated with records management, FOIA, privacy, and data security. They can be used to create audit trails, which help with data-driven regulatory requirements related to data security and access, the status of any FOIA requests, and whether the data are currently available online or are archived. Operational or administrative metadata reduce overhead in data administration by providing adequate documentation relating to the current state of the data.

Technical Metadata. Technical metadata are often managed by personnel that are not directly responsible for the data. They should be created at the point where a database or dataset is designed or developed. They include information about physical implementation and delivery of the data such as the assigned Digital Object Identifier for the digital data publication, reference to the data-hosting site or service, the 
actual date of release, and any references to documentation relating to application program interfaces (API) if used for content delivery.

Dependencies. This action requires executive support, adequate resources, and initial project approval to begin work. Staff must possess the necessary skills and have a clear understanding of their roles and responsibilities in the data and metadata lifecycle.

Responsible Roles. Many individuals are involved in providing metadata profile content for each metadata type. Data originators, data architects, modelers, subject matter experts, and data stewards provide much of the content for business metadata. Data stewards, system and data managers, FOIA, and data security representatives are responsible for operational metadata. Individuals who design and develop the physical implementation of the dataset and those involved with publication approval, hosting services, Application Program Interfaces development, and the delivery of the data are involved in documenting technical metadata.

\section{Deliverables}

1. A list of potential associated metadata standards that meet the required level of documentation needed for each metadata type and source.

2. The required level of documentation needed for each type of metadata.

3. A prioritized list of datasets that may need additional documentation across the three metadata types.

\section{Measurement}

The following are questions that can be used to evaluate the completeness of business, operational, and technical metadata.

Business Metadata. To evaluate your organization's practices related to business metadata, answer the following questions:

1. How does your organization capture data requirements for investments and projects?

2. Where are business metadata documented, and where are they stored for reuse for other projects? Are the business metadata available across the organization?

3. Who is responsible for the business metadata, and how are they shared within and outside of the organization(s)?

4. Are definitions or domain values for the same data element different between databases or datasets of similar theme or data domain?

5. Have standards been reviewed to ensure consistency and clarity regarding data definitions and relations across the organization?
6. Is there policy related to business metadata, including naming conventions?

7. Are all parties that create and use the data involved in developing the business metadata?

8. How well are your legacy databases documented with respect to metadata?

Operational Metadata. To evaluate your organization's practices related to operational metadata, review the following

1. Who is responsible for operational metadata and the associated requirements?

2. How have operational metadata been captured, updated, stored, documented and shared?

3. Are metadata elements consistently defined across all metadata needs?

4. How are operational metadata governed and managed?

Technical Metadata. To evaluate your organization's practices related to technical metadata, review the following

1. How well is your organization capturing data hosting and data growth requirements for data capacity planning?

2. Who is responsible for the final completion and validation of the technical metadata?

3. Can a metadata governance process be developed around the final validation and acceptance of the entire metadata profile prior to release or publication?

4. Are those responsible for data hosting and data security flagging the existence of metadata referencing proprietary and sensitive data that may require special attention to avoid public release or access to other metadata catalogs?

5. Does your organization have technical metadata standards?

6. Do you have technical metadata that link to the data dictionary and related business metadata?

Recommended Methods and Tools. References for metadata implementation, best practices, and case studies.

\section{Action 1.3. Establish Roles and Identify Points of Contact}

Drivers. Identification of representatives who oversee metadata-related activities is necessary to support and implement metadata management. This network of metadata professionals serves as the foundation for implementing successful metadata management throughout the data lifecycle.

Description. Bureaus and offices may use the roles described in table 2 as a common guide to refine roles and responsibilities. For each of the applicable responsibilities and functional roles, one or more staff should be identified with their name, title, and contact information. 
Table 2. Employees and other data management personnel and their functional role(s).

\begin{tabular}{|c|c|}
\hline Personnel identified in implementation & Functional roles and responsibilities \\
\hline \multirow[t]{2}{*}{ Department of the Interior (DOI) } & $\begin{array}{l}\text { Overarching agency policy, cross bureau and office coordination, strategy, } \\
\text { standards, and guidance (templates), DOI motivation for compliance, } \\
\text { evaluation metrics, technical tool guidance/toolbox. Operational support } \\
\text { regarding the DOI Metadata Catalog. Office of Management and Budget } \\
\text { reporting of the DOI Enterprise Data Inventory. }\end{array}$ \\
\hline & $\begin{array}{l}\text { Create and update implementation guide, metadata data quality, continuity, and } \\
\text { legacy; bureau program level motivation for compliance. Overall sponsorship. }\end{array}$ \\
\hline $\begin{array}{l}\text { Bureau/office: executives and lead scientists/principal } \\
\text { investigators }\end{array}$ & $\begin{array}{l}\text { Support metadata and data management. Request funds regarding metadata } \\
\text { and data management at the Program level. Operational support (people, } \\
\text { time, money). }\end{array}$ \\
\hline $\begin{array}{l}\text { Bureau/office/program: center directors, open data points } \\
\text { of contact (people responding to open data policy), data } \\
\text { managers }\end{array}$ & $\begin{array}{l}\text { Support and implement metadata and data management. Request funds } \\
\text { regarding metadata and data management at the Bureau Program level. } \\
\text { Operational support (people, time, money). Performance metrics }\end{array}$ \\
\hline $\begin{array}{l}\text { Bureau/office/program: system managers, data stewards, } \\
\text { data creators, metadata creators }\end{array}$ & $\begin{array}{l}\text { Operational support for metadata and data management at the Project and } \\
\text { task level. }\end{array}$ \\
\hline $\begin{array}{l}\text { Bureau/office/program: data collectors, data producers, } \\
\text { analytical lab personnel, project/task managers }\end{array}$ & $\begin{array}{l}\text { Adherence to metadata and data standards, QA/QC, and overall metadata } \\
\text { operational implementation within a project or task. }\end{array}$ \\
\hline $\begin{array}{l}\text { Bureau/office/program: grantees, contractors, citizen scien- } \\
\text { tists, public, scientist }\end{array}$ & $\begin{array}{l}\text { Adherence to metadata and data standards, QA/QC, and overall metadata } \\
\text { operational implementation within a project or task that has a grant, } \\
\text { contract, or external (citizen science) data collection component. }\end{array}$ \\
\hline
\end{tabular}

Dependencies. The bureau or office has the necessary executive support, staff availability, and resources to begin identifying and assigning roles for metadata implementation.

Responsible Roles. Bureau or office leadership assigns key data management professionals to the appropriate tasks.

\section{Deliverables}

1. List of bureau or office points of contact with their associated roles and responsibilities.

\section{Measurement}

1. At least one identified point of contact with an associated role within a particular subject area.

Recommended Methods and Tools. References for metadata implementation, best practices, and case studies.

\section{Action 1.4. Participate in Metadata Communities of Practice}

Drivers. Participating in metadata communities and groups can help those responsible for metadata gain knowledge of metadata methods, standards, and best practices implemented by others, and also develop relations and lines of communication within and among bureaus and offices or external partners that facilitate the exchange of metadata knowledge.

Description. This action encourages internal and external metadata collaboration efforts. Sharing information will result in a more consistent and successful approach in managing metadata, often saving time and money.

Dependencies. The success of this action is dependent on the ability of the DOI Office of the Chief Information Officer (OCIO) and the bureaus and offices to host metadata information sessions with external metadata groups and data domain representatives.

Responsible Roles. Agency and bureau or office leadership and data management professionals and key stakeholders participate in relevant groups.

\section{Deliverables}

1. List of scheduled collaboration sessions to share experiences, processes, documents, and other relevant information.

2. List of potential avenues for metadata collaboration with groups that may have applicable sessions, presentations, or information exchange forums.

3. List of standards, processes, and procedures used across these communities that may benefit your organization. 


\section{Measurement}

1. At least one information session hosted or attended per quarter.

2. List of relevant standards, processes and procedures.

3. Recommended Methods and Tools. References for metadata implementation, best practices, and case studies.

\section{Action 1.5. Develop Communication Strategy}

Drivers. Develop a shared or common dictionary to ensure consistent use of metadata related terms and definitions and enable coordination of metadata implementation efforts within and across bureaus and offices. This is necessary to develop consistency and communicate the value of metadata and data management for the organization.

Description. Communicating metadata management requirements is an important aspect of implementation. Metadata implementation needs to be communicated to executives, system managers, practitioners, and stakeholders, highlighting the importance of metadata management for achieving mission goals, encouraging staff at all levels to engage in metadata management, integrating metadata management into the data lifecycle, managing change within the organization, and providing an overview of metadata management requirements, deliverables, and metrics for successful implementation. An important component to communication is to educate staff about metadata concepts using consistent terminology.

Dependencies. Metadata has been adopted and an initial metadata management implementation guide is available.

Responsible Roles. Bureaus or offices with assistance from DOI OCIO and DOI Data Services Team (DST) members, communication staff, and other bureau or office representatives as appropriate will help coordinate communications.

\section{Deliverables}

1. High-level presentation that can be modified to include specific bureau or office information as needed.

2. Communication Plan.

3. Fact sheet or other information sheet highlighting the value of implementing metadata management.

\section{Measurement}

1. Current presentation and fact sheet describing the metadata implementation effort within three months of management approval.

2. Conduct survey to evaluate awareness and understanding of metadata and associated available resources.

Recommended Methods and Tools. References for metadata implementation, best practices, and case studies.

\section{Action 1.6. Identify Metadata Standards}

Drivers. A standards-based approach provides consistency in metadata across and between organizations for those who enter, manage, and use metadata. Standards facilitate data discovery and sharing and management of metadata in the DOI Metadata Catalog. Various metadata standards can be applied to data, and it is important to identify the most appropriate standard for reuse rather than to develop new standards.

Description. Metadata standards help facilitate metadata creation, metadata and data management, and data publication across DOI. This guide addresses broad requirements for standards in support of data resource management. Bureaus and offices should use applicable metadata standards and may recommend additional metadata requirements based on organizational requirements, standards, specifications, or formats developed within different communities (for example, earth science, financial, health, geospatial, and law enforcement). The MIG does not supersede ongoing metadata activities in any bureau or office, but rather provides information about how to meet metadata management requirements.

Dependencies. The bureaus and offices must have knowledgeable staff in place to identify applicable metadata standards. This requires knowledge of existing standards and how well they meet bureau or office data documentation requirements.

Responsible Roles. Data stewards, lines of business representatives, and the DOI DST with assistance from the DOI OCIO are responsible for identifying and implementing appropriate standards.

\section{Deliverables}

1. Inventory of current metadata standards used in bureau or office.

2. Plan for how metadata fulfills Federal requirements.

3. List of acceptable metadata standards that the bureau or office will adopt and enforce.

\section{Measurement}

1. List of applicable metadata standards that meet organization requirements.

2. Measure progress and extent of activity in bureau or offices in regards to implementing the selected metadata standards.

Recommended Methods and Tools. References for metadata implementation, best practices, and case studies.

\section{Action 1.7. Select Metadata Management Tools}

Drivers. Business requirements and metadata standards drive the selection of tools and applications that best support overall metadata management goals and objectives. 
Description. Metadata management tools and applications greatly improve the efficiency of overall metadata management.

Dependencies. Adequate staff is available to formulate and select appropriate metadata tools and applications that meet metadata management requirements. Bureaus and offices engage with DOI OCIO, and OCIO is able to serve a coordinating function to maximize consistency.

Responsible Roles. Business leads, data managers, data stewards, data originators, and representatives from FOIA, data security, and records management provide input into metadata requirements, standards, and selection of appropriate metadata tools and applications. Metadata technical leads evaluate metadata requirements against existing metadata management tools and applications and create metadata management tools and applications only where none exist. The DOI OCIO and DOI DST coordinate and share information, and promote the inventory of selected metadata tools and applications across DOI.

\section{Deliverables}

1. List of requirements and standards that drive metadata tool and application selection process.

2. Bureau or office inventory of metadata tools and applications that meet metadata management requirements. This inventory should include those already implemented throughout DOI.

\section{Measurement}

1. The percentage completion of an inventory of metadata tools and applications that best meet designated requirements.

2. Level of adoption and use of these tools across the bureau or office.

Recommended Methods and Tools. References for metadata implementation, best practices, and case studies.

\section{Phase II. Implement and Manage Metadata}

Phase II builds on prior planning actions by implementing processes and workflows for metadata creation, management, and publication that can become the framework for long-term metadata management.

\section{Action 2.1. Create and Maintain Metadata}

Drivers. The purpose is to establish a repeatable approach to operationalize enterprise metadata management and meet Federal requirements for publishing metadata.

Description. A bureau or office creates or updates metadata using relevant standards and selected tools (see section Action 1.7 Select Metadata Management Tools).
Maintaining a bureau or office metadata catalog with metadata tags can (1) facilitate data community delineation and advanced metadata search for data discovery, data geographic location, and digital object identifiers, and (2) ensure minimum metadata requirements.

A key component of this process is developing and maintaining business metadata. Developing business metadata requires stakeholder engagement and buy-in across the organization, especially with regard to consistent definitions for business and scientific terms. Once the terms are defined, they can be used across the organization for future data.

Metadata and data release governance is important throughout the process of metadata creation and publication. Publishing metadata necessitates complete business, operational, and technical metadata based on bureau or office needs, policies, and recommended best practices. For any data or metadata that might have sensitivity considerations, bureaus and offices should consult with their records management, FOIA staff, or other designated contacts responsible for proprietary data.

Dependencies. Bureaus and offices have identified staff with clear roles and responsibilities for this task. Standards, practices, and tools have been identified and are in place to support efforts related to this action.

Responsible Roles. Bureau or office scientists, project and task administrators, data stewards, data creators, and data producers are engaged in metadata management implementation with assistance from other bureau or office representatives, as appropriate.

\section{Deliverables}

1. Metadata records with complete business, operational, and technical metadata for all bureau or office datasets.

2. Metadata records maintained in a bureau or office metadata catalog or another application that can be published to the DOI Metadata Catalog.

\section{Measurement}

1. Percent of datasets meeting the minimum population of standards-based metadata.

2. Percent of datasets with standards-compliant metadata.

3. Percent of metadata meeting or exceeding relevant quality standard(s).

Recommended Methods and Tools. References for metadata implementation, best practices, and case studies.

\section{Action 2.2. Publish Metadata}

Drivers. The purpose is to increase data visibility and access through a consolidated index of metadata records.

Description. Once a bureau or office has created complete metadata records, they should be published to the specified 
metadata catalog to create a searchable index of data assets. This metadata catalog provides a method to increase data visibility across the Department and for the public. A bureau or office might establish their own internal metadata catalog or partner to share metadata catalog technology. However, all bureaus and offices must register and publish metadata to the DOI Metadata Catalog, which was established by DOI to facilitate a single source for all metadata (fig. 2). In addition to being an enterprise-level source of metadata, the DOI Metadata Catalog system represents the source for DOI metadata provided to other catalogs (such as Data.gov).

Dependencies. The DOI OCIO provides support for implementation and maintenance of the DOI Metadata Catalog and ensures that there is the necessary staff with the technical capabilities to implement the DOI Metadata Catalog publishing procedures.

Bureaus and offices need to prepare their respective metadata prior to publishing them to the DOI Metadata Catalog. The following are items that each bureau and office should consider throughout the process.

1. Verify that all metadata records are designated appropriately as either public or nonpublic.

2. Validate currency, provenance, and links to the data to ensure metadata are accurate and trusted.
3. Adopt best practices and workflows with regard to the external federated metadata catalog.

4. Ensure metadata requirements are included in, and being satisfied under, bureau or office grants, interagency or interbureau agreements, and contracts.

5. Metadata validation and data-quality checks should be completed prior to bureau or office publication.

Responsible Roles. The DOI OCIO, the DOI data governance body, and the DOI DST provide technical tools and guidance with respect to the DOI Metadata Catalog and external metadata catalogs. Key bureau and office personnel ensure that metadata publication is being executed in compliance with publication guidelines across the organization.

\section{Deliverables}

1. Current DOI Metadata Catalog, with each metadata record flagged as public or nonpublic.

\section{Measurement}

1. Percent increase of mission critical data registered in the DOI Metadata Catalog.

Recommended Methods and Tools. References for metadata implementation, best practices, and case studies.

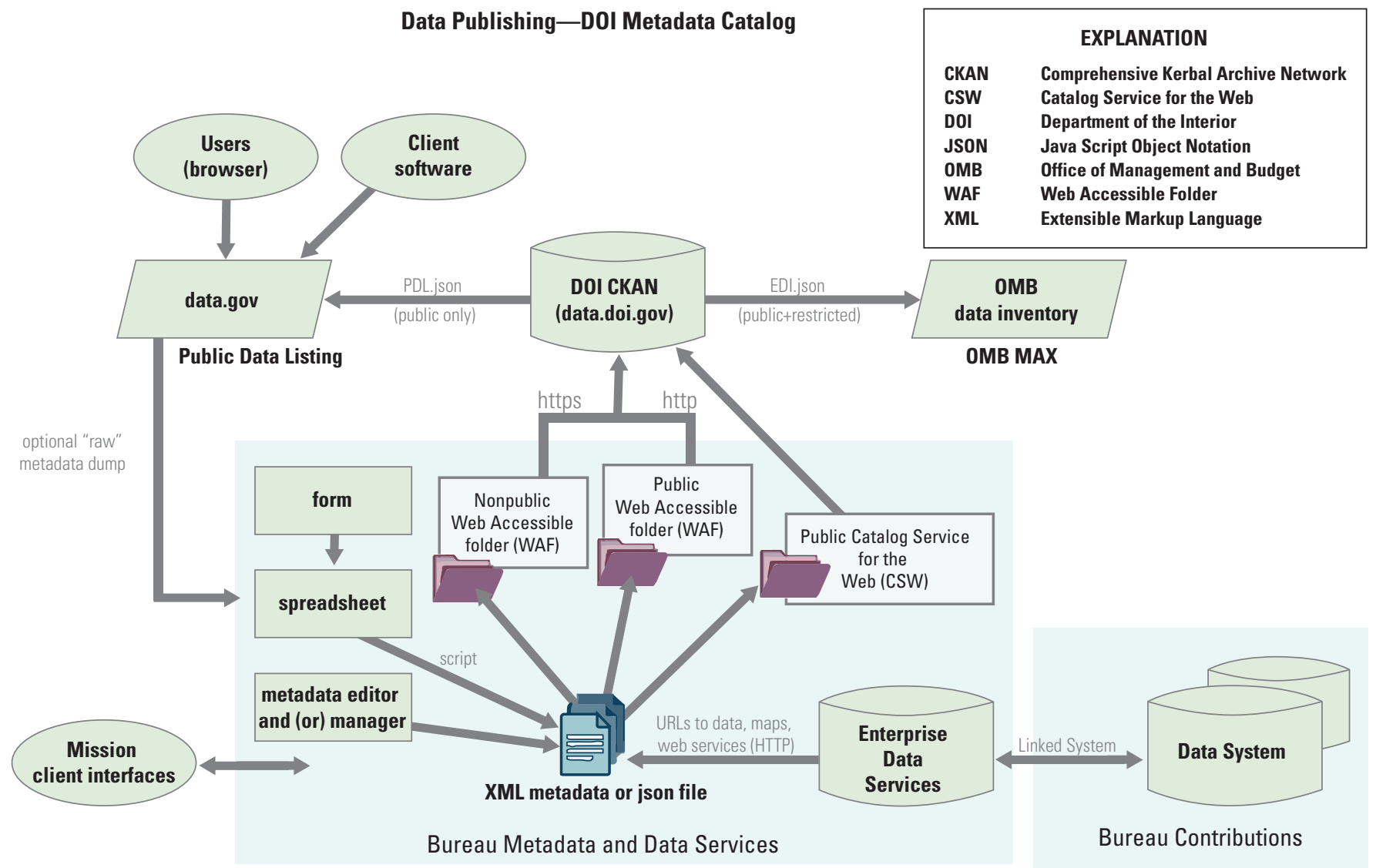

Figure 2. Publishing metadata to the DOI Metadata Catalog (from Frame and Wheeler, 2014). 


\section{Phase III. Improving Metadata Management}

This phase focuses on next steps to enhance metadata management once the minimum requirements of planning and executing a basic metadata program have been satisfied. These steps provide a consistent approach to metadata evaluation, metadata quality, and data architecture for data hosting, data services, metadata catalog, and overall metadata management across all functional areas. Investments in metadata management make it sustainable and functionally robust for the organization. Through continual refinement, metadata management becomes a routine operational task that promotes data as an asset for improved program operations, research analytics, and decision making.

\section{Action 3.1. Evaluate Metadata Implementation}

Drivers. Evaluation may be needed when a bureau or office considers improvement to its overall metadata management to prioritize the data domains and metadata areas that need improvement. Evaluations should be conducted on a recurring basis as part of metadata management.

Description. Metadata management evaluation allows bureaus and offices to measure the effectiveness of steps that have been or will be taken to improve or maintain metadata. Incorporating a variety of perspectives and different sources of information to achieve the desired degree of internal assessment may be necessary.

Rigorous evaluation applies gathering of statistics that indicate the relevance, usability, quality, and purpose of data. Statistics gathering is accomplished through tools such as direct observations of metadata, surveys, polls, and questionnaires to see how well the data are meeting customer needs. Statistics might also include the rate of website or web page visits and dataset downloads, the results of a randomized user questionnaire, or an actual user experience interview.

Dependencies. Staff undertaking the evaluation must have sufficient knowledge of the organization and a clear understanding of the guidelines of metadata implementation. They should understand the questions that they are tasked with addressing and to whom the evaluation outcomes will be reported. For organizations with existing metadata best practices and compliance standards, performance metrics and indicators need to be part of the organization's metadata management to enable adequate assessments.

To evaluate user statistics, data creators must be available to develop measurements to understand data consumption and use by internal users and cooperators and the public. Staff also needs support from web portal administrators to configure the proper analytical tools to capture web statistics and web survey responses.

Responsible Roles. Bureau or office leadership, data creators, metadata management leads, web administrators, communications staff, and data stewards develop metrics to measure performance and participate in program evaluation.

\section{Deliverables}

Guidance is delivered to bureaus and offices to provide the means to improve their metadata programs. This might include

1. An evaluation that rates the maturity of metadata management within the organization, and defines objectives and goals for organizational change;

2. A list of recommended approaches or activities that address perceived barriers to change, provide meaningful progress in the short term, and deliver successful outcomes in the long term;

3. A list of performance metrics and success indicators that are recommended for use by the organization's leadership to track progress;

4. Other recommended systems of metrics to focus time and energy and solve problems that may arise, for example, a list of metrics to track who is using the specific data being published, and how the data are being used;

5. Survey results indicating whether data are meeting the user's needs or expectations and other information regarding how the data benefit the consumer; and

6. Assignment of a person with a lead role and responsibility to be accountable to organizational management to follow up on recommendations and findings from the evaluation.

\section{Measurement}

1. Ranking of the organization's data maturity level (see the capability maturity model integration's data management maturity capability levels (CMMI DMM) and definitions in table 3).

2. Level of completion of recommendations to improve data maturity level based on identified metrics.

3. User statistics that indicate the number and type of end users, what data are being used, and how the data are being used.

The data management maturity can be measured using the following CMMI DMM capability levels.

Recommended Methods and Tools. References for metadata implementation, best practices, and case studies.

\section{Action 3.2. Develop and Enforce Metadata Quality Standards}

Drivers. The purpose is to provide consistently high-quality and robust documentation of data to conduct science and business activities and support bureau or office decision making. 
Table 3. Metadata management capability (maturity) levels of design structure matrix (DMS) (copyright CMMI Institute, 2014).

\begin{tabular}{|c|c|c|}
\hline Level & Capability maturity indicators & Functional practices \\
\hline 1. Performed & Metadata documentation is developed, stored, and accessible. & Basic metadata documentation exists. \\
\hline 2. Managed & $\begin{array}{l}\text { Metadata management follows a process, captures data } \\
\text { interdependencies, and is used to perform impact analysis }\end{array}$ & $\begin{array}{l}\text { Metadata process, interdependency documents, } \\
\text { impact analysis, metadata architecture exist. }\end{array}$ \\
\hline 3. Defined & $\begin{array}{l}\text { There is a metadata strategy promoted and maintained by } \\
\text { governance. A metadata repository is populated with expanded } \\
\text { metadata categories, management is centralized, and governance is } \\
\text { integrally involved in development and maintenance of metadata. }\end{array}$ & $\begin{array}{l}\text { Centralized functions, metadata strategy exists, } \\
\text { and governance oversight is in place, process } \\
\text { metrics are used, expanded architecture and } \\
\text { implementation, architectural validation occurs. }\end{array}$ \\
\hline 4. Measured & $\begin{array}{l}\text { An integrated meta-model is developed, metadata types and } \\
\text { definitions are consistently applied, exchange data representation } \\
\text { standards are addressed, metrics guide metadata improvements } \\
\text { and quantitative objectives are developed and followed. }\end{array}$ & $\begin{array}{l}\text { Integrated metadata model, consistent import, } \\
\text { subscription, and consumption of data, metrics } \\
\text { driven improvements, metric inspired additions, } \\
\text { quantitative objectives, statistical analysis, } \\
\text { exchange data standards }\end{array}$ \\
\hline
\end{tabular}

Description. Metadata quality metrics indicate how well the metadata support program requirements, decision making, and current and future business demands. Validation helps assess the quality characteristics of the metadata, including their accuracy, completeness, currency, consistency, and integrity. The functions of metadata quality metrics and validation tools can be automated to process metadata more efficiently and consistently at the point of metadata creation.

Dependencies. Data professionals need to have access to and engage with the bureau or office leads to document business requirements for metadata quality. Complete and functional metadata creation and validation tools need to be available to meet bureau or office metadata management requirements. End users will have received training on metadata quality requirements and how to use metadata creation tools.

Responsible Roles. Bureau or office metadata management leads, business and science program or mission leads, data managers, data stewards, data creators, metadata creators, open data points of contact, and application developers are knowledgeable about metadata standards and how they are appropriately implemented.

\section{Deliverables}

1. List of approved metadata quality requirements.

2. Metadata quality metrics.

3. Metadata authoring tool to help automate metadata QA/ QC process and validation.

4. Approved metadata training program.

5. Metadata conversion tool to import and export metadata between standards.

\section{Measurement}

1. Approved and defined metadata quality metrics are implemented throughout the organization.

2. Metadata are scored against quality metrics.

3. Percentage of metadata that can be verified as authoritative.

4. Percentage of staff that has completed relevant training.

5. Adoption of approved metadata management tools.

6. Reduction of system-generated metadata quality exceptions.

Recommended Methods and Tools. References for metadata implementation, best practices, and case studies.

\section{Action 3.3. Create Shared Metadata and Metadata Infrastructure}

Drivers. The purposes are to create awareness and understanding of data and information resources, improve the value of the data and metadata implementation, and increase the efficiency with which metadata management requirements may be achieved by creating the necessary metadata management and content delivery infrastructure for federating metadata across the organization. Creating a single trusted source for organizational data enhances the user's ability to search, find, manage and use bureau or office authoritative data on a routine basis.

Description. Roles and responsibilities, processes, and tools are defined and integrated into enterprise metadata management 
for collecting and executing metadata requirements. This includes all aspects of business, technical, and operational metadata.

For example, a bureau or office metadata catalog is created and maintained for managing unique references to authoritative data assets in a single access point and consistent view. The catalog includes a dashboard which addresses bureau or office needs for data search, discovery, and use. The catalog is a trusted source for accessing enterprise data that uses an agreed-upon business metadata repository (data dictionary) and serves as a shared medium of communication among all the organizational units.

Dependencies. Bureau or office personnel must have the technical expertise for data and metadata management. Enterprise metadata management must also be integrated into business processes and functions, and receive enterprise support for continued process improvement and business system integration. Additionally, personnel must have technical expertise in installing, configuring and running metadata catalog software, the computer server hardware necessary to run the catalog, and developer expertise required to facilitate the buildout of the catalog dashboard, metadata APIs, and any necessary tools and utilities.

Responsible Roles. Data professionals issue guidance, define tasks, and establish business metadata requirements. Business analysts, data modelers, subject matter experts, and data stewards are responsible for creating and maintaining the business metadata. Data stewards and program staff create and maintain technical and operational metadata. System administrators and application developers have a role in standing up and operating the bureau catalog. Executives, management, investment sponsors, data stewards, and data owners support metadata functions and operational aspects of the catalog. Project managers implement projects in compliance with guidance and best practices.

\section{Deliverables}

1. Standardized operating procedures, policies, protocols, governance, IT systems, and change management processes.

2. A functioning metadata catalog infrastructure that provides critical metadata management capabilities to staff.

3. A harvest source for authoritative bureau or office metadata for publication to federated catalogs.

4. Documented workflow that cross-references data security, records management, FOIA, privacy, legal, communications, acquisitions, and contracting requirements.

\section{Measurement}

1. Increased number of records in the metadata catalog over time.
2. Percentage of lines of business contributing to and using the metadata catalog.

3. Average data catalog user session time to search, discover, and access data.

4. Number of projects or initiatives that reuse existing data.

5. Percentage of bureau or office data assets displayed in the catalog user interface.

6. Assessment of catalog content for uniqueness, relevance, and authority.

7. Percentage of metadata records that have been classified and tagged appropriately based on data security, records management, FOIA, privacy, legal, communications, acquisitions, and contracting administrative requirements.

Recommended Methods and Tools. References for metadata implementation, best practices, and case studies.

\section{Action 3.4. Increase Data Access and Usability for Target Audiences}

Drivers. The purpose is to enable bureaus and offices to make their data accessible, usable, understandable, and easily integrated in a specific context through customization of data access and delivery mechanisms. An important ingredient to achieving open access for Federal data and metadata are standards for interoperability.

Description. Machines are programmed using application program interfaces (API) as a medium to access data. Standards for data access and transport help enable API interoperability and reuse. Metadata play an integral part in APIs by providing context to the data content and a gateway to intelligently access and display the data. For example, machines are programmed to obtain data from APIs for transformation into other usable formats or support web applications that (1) display data for various visualizations such as charts, graphs, maps, and map services, and (2) facilitate data download.

APIs may also assist search and discovery through customized queries of metadata that can promote increased data reusability and integration across the organization. APIs are a relatively small investment that leverages the metadata investments of the government, enabling the development of numerous applications that exponentially multiply the number and kinds of access to data across the public, private, and government sectors.

Dependencies. Bureaus and offices need to have high-quality data and metadata that meet basic content and format standards to enable provision of data and information. In cases for which custom APIs will be created for serving bureau or office data, the requirements for serving data need to be understood and documented. API technical experts will need to work with the appropriate project team, data stewards or creators, and application developers to determine API requirements. 
For external audiences, the bureaus and offices need to identify user communities that can be targeted for serving metadata and resulting data in a format that bests meets the end users' needs and expectations. Conducting a cost-benefit analysis of proposed APIs and using open-source standards to promote reusability and data interoperability will yield investments that maximize overall benefit and favor the developer's recommendation to invest in new API technology.

Responsible Roles. Data creators, data stewards, bureau program managers, project and task leaders, and application and developers must be involved in the identification of requirements and development of APIs.

\section{Deliverables}

1. Strategic datasets are identified and prioritized for API development.

2. Open-source or community-maintained APIs are developed and implemented.

3. New API technology is created when API technology cannot be identified to support high-priority requirements.

4. Policy and governance for API development, use, and dissemination.

\section{Measurement}

1. APIs are registered in the DOI Metadata Catalog, using appropriate service level metadata documentation.

2. Percentage increase in the number of applications created and deployed.

3. Increased customer satisfaction.

4. Decreased user support requests.

Recommended Methods and Tools. References for metadata implementation, best practices, and case studies.

\section{References}

Capability Maturity Model Integration Institute [CMMI], 2014, Data Management Maturity [DMM] Model, Capability Maturity Model Integration Institute, 248 p.

Early, Susan, ed., 2011, The DAMA dictionary of data management ( $2 \mathrm{~d}$ ed.): Data Management Association International Technics Publication, $254 \mathrm{p}$.

Frame, Mike, and Wheeler, Ben, 2014, USGS community for data integration, Data management Working Group: U.S. Geological Survey Science Data Catalog, Open Data Discussion, 18 p., accessed October 25, 2017, at https://my.usgs. gov/confluence/download/attachments/518429926/CDI\%20 Data\%20Mgmt.\%20WG\%20Prez\%2011\%2010\%2014.pdf?v ersion=1\&modificationDate $=1415653524742 \&$ api $=v 2$.

Mecca, Melanie, 2014, Data management maturity model introduction: University of Ottawa, 53 p., accessed October 25, 2017, at http://c.ymcdn.com/sites/www.globalaea. org/resource/collection/68814379-BF7E-41C8-B15218A617F9C0AA/Data_Management_Maturity_Model_ Introduction_-_Dec_12_2014.pdf.

Mosley, Mark, Brackett, Michael, and Earley, Susan, eds., 2009, The DAMA guide to the data management body of knowledge (1st ed.): Data Management Association International Technics Publication, $430 \mathrm{p}$.

National Information Standards Organization, 2004, Understanding metadata: NISO Press, 49 p., accessed October 25, 2017, at http://www.niso.org/standards/resources/UnderstandingMetadata.pdf.

Office of Management and Budget, 2013 [OMB], 2013, Open data policy-Managing information as an asset: Office of Management and Budget Memorandum M-13-13, 12 p., accessed October 25, 2017, at https:// obamawhitehouse.archives.gov/sites/default/files/omb/ memoranda/2013/m-13-13.pdf. [Also available at https:// project-open-data.cio.gov/policy-memo/.] 



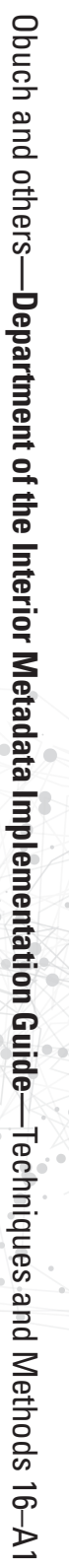

